\title{
Profile of physical activity in the pregnant women coari city, Amazon
}

\begin{abstract}
Physical inactivity Has Been During pregnancy outcomes associated with detrimental for the mother and fetus, regular physical activity is Indicated are pregnant women is due to the maternal and fetal benefits That can act in the short and long term. The aim of the study was to characterize the expenditure of energy on physical activity in low-risk pregnant women living in the municipality of TNL-AM. A cross-sectional descriptive study carried at basic health unity. 50 Volunteers in 12th and 36th week gestational age composed it. Data Were collected through the Physical Activity Questionnaire for pregnant women (QAFG), classified the sample Which the insufficiently active and active. Before pregnancy $56 \%$ of the sample Practiced some type of physical activity and During pregnancy there was a reduction to only $32 \%$. The date Showed the prevalence of active pregnant women in domestic tasks $(56 \%)$ and locomotion $(74 \%)$, and pregnant women insufficiently active in caring for people (64\%), occupation (66\%), sports $(94 \%)$ and leisure $66 \%)$. The average energy intensity spent weekly on the tasks Evaluated did not show statistical difference When Compared to the groups (second and third gestational trimesters). The study Showed que pregnant women During Were active domestic tasks/locomotion and sedentary or not active in tasks related to sports/exercise, leisure, caring for people and occupation. Is Necessary an incentive to practice physical activity in this period by professionals of health. sports (94\%) and leisure 66\%). The average energy intensity spent weekly on the tasks Evaluated did not show statistical difference When Compared to the groups (second and third gestational trimesters). The study Showed que pregnant women During Were active domestic tasks locomotion and sedentary or not active in tasks related to sports/ exercise, leisure, caring for people and occupation. Is Necessary an incentive to practice physical activity in this period by professionals of health. sports (94\%) and leisure 66\%). The average energy intensity spent weekly on the tasks Evaluated did not show statistical difference When Compared to the groups (second and third gestational trimesters). The study Showed que pregnant women During Were active domestic tasks/ locomotion and sedentary or not active in tasks related to sports/exercise, leisure, caring for people and occupation. Is Necessary an incentive to practice physical activity in this period by professionals of health.
\end{abstract}

Keywords: physical exertion, sedentary lifestyle, pregnancy
Volume 4 Issue 4 - 2019

\author{
Maria Luciana Moura de Matos, Cleuzenir \\ Melo Nunes, Ercilia de Souza Andrade, \\ Gabrielle Silveira Rocha Matos \\ Federal University of Amazonas, Institute for Health and \\ Biotechnology, Brazil
}

\begin{abstract}
Correspondence: Gabrielle Silveira Rocha Matos, Federal University of Amazonas, Institute for Health and Biotechnology, Coari,Amazonas, CEP 69460-000, Brazil,Tel +55(92)99131-1764, Email gabrielle_srm@hotmail.com
\end{abstract}

Received: July 09, 2019 | Published: July 18, 2019

\section{Introduction}

Pregnancy is a period that begins at conception, extends for about 40 weeks and ends with childbirth. ${ }^{1}$ During this period the pregnant woman undergoes several and significant modifications in the body that determine diverse physiological transformations. ${ }^{2,3}$ These changes affect the cardiorespiratory, musculoskeletal and general metabolic system, being not limited only to the organs but also the female body mechanics, being mainly due to the hormonal changes responsible for the adaptations of the organism to its new condition. ${ }^{4}$

Any spontaneous bodily movement that results in an energy expenditure greater than that spent at rest is called physical activity, in turn physical exercise is defined as any organized, planned and repetitive physical activity that aims at improving health and maintaining one or more component of physical capacity. ${ }^{5,6}$ The lack of physical activity, not only in the character of sports practice, but in all its amplitude is denominated sedentarismo. ${ }^{7}$

The sedentary lifestyle is more perceived in women during pregnancy than in the general population, ${ }^{8}$ although the maintenance of a rhythm of physical activities with precautions is the most recommended to make pre- and postpartum much calmer and more advantageous. ${ }^{9}$
The practice of physical activity in the gestational period was recognized in 2002 as a safe activity, suitable for all healthy pregnant women. ${ }^{5}$ Such practices help to control weight, maintain the physical conditioning of the mother, prevent and reduce musculoskeletal pain and edema, as well as improve aerobic capacity directly related to the reduction of labor in healthy mothers ${ }^{10}$ and also enables return to weight in a healthy puerperal condition, providing a more pleasurable, pleasant and comfortable postpartum and breastfeeding period. ${ }^{5,9}$

However, with so many physiological changes the psychological state of pregnant women is also changed, so that there is an accommodation and discouragement to perform physical activities such as hiking, specific physical exercises and other activities of this nature, which determines a condition sedentary lifestyle, favoring the reduction of physical conditioning that period. ${ }^{2}$

Thus, physical inactivity during pregnancy has been associated with adverse outcomes for both the mother and the fetus, having been singled out the excessive weight gain, obesity, gestational diabetes, preeclampsia / eclampsia, premature birth and low birth weight as the main results. ${ }^{11}$

In Brazil, some studies have shown highly alarming data is treating the active lifestyle of pregnant women ${ }^{5}$. In the city of Coari- 
$\mathrm{AM}$, an analysis of pregnant teenagers indicated a prevalence of $75 \%$ considerably sedentary volunteers with low and inappropriate level of activity since the beginning of gestation. ${ }^{2}$ To public health, physical inactivity during pregnancy appears to be a modifiable risk factor for the prevention of harm, and constitutes an ever-present factor in developed countries. For this reason, actions aimed at increasing the number of active pregnant are created and tested with promising results. ${ }^{8}$

Therefore, considering that the accomplishment of physical activity brings innumerable benefits to the woman from pregnancy to postpartum and that managers and health professionals should recognize and stimulate this practice, it is considered for this study that an active lifestyle of form system inserted in the prenatal program is the most suitable for the planning of health actions.

This study aimed to characterize the pattern of metabolic expenditure during physical activity in low-risk pregnant women living in the municipality of Coari-AM.

\section{Methods}

This study is a cross-sectional characcally descriptive, held in Basic Health Units (BHU) in the city of Coari, Amazonas State, from August 2017 to July 2018. The work was aimed at pregnant women in gestational period between 12th to 36th week, and the sampling process of the simple random type. They interviewed 79 pregnant women enrolled in the SIS PRENATAL by UBS study. They were included women over 18 years undiagnosed risk pregnancy. volunteers were excluded who chose not to answer all the research protocol or occurrence of risk to normal pregnancy cycle during the study. Finally, the sample was composed of 50 volunteers.

Contact with the voluntary survey took place after approval by the ethics committee in research in accordance with the terms of Resolution no. 466/12 from National Health Council of the Ministry of Health of Brazil. The volunteers have confirmed their participation in the study after reading and signing of the consent form (ICF). The study was approved by the ethics committee and the Federal University of Amazonas (Amazonas University), technical advice number 2019752 under CAAE 65792417.4.0000.5020.

The volunteers answered a structured questionnaire developed for this study in order to collect personal data, demographic and health partners. Then they were asked to answer the questionnaire pregnancy physical activity questionnaire (PPAQ), translated and adapted to brasilian population. ${ }^{12}$ This assessment tool determines the energy expenditure metabolic equivalents (METs) in different activities of daily life and physical (domestic chores, caring for others, leisure, mobility, exercise / sports and occupation).

For analysis the sample was divided into two groups, according to gestational age: Second trimester (12 to 23 weeks gestation) and third trimester (24 to 36 weeks gestation). The physical activity pattern was analyzed for different activities of daily life and physical. For each activity, the patients were classified according to intensity determined by PPAQ: Sedentary $(<1.5 \mathrm{METs})$, mild $(1.5<3.0 \mathrm{METs})$, moderate (3.0<6.0 METs) or vigorous $(\geq 6.0$ METs). The sample wasclassified as insufficiently active (sedentary or slightly active) and active (moderate or vigorously active).

The weekly intensity of physical activity of pregnant women,ie expended energy expenditure relating to different types of physical activity was calculated in METs following PPAQ guidelines.
The statistical analysis was performed through the use of software Statistical Package For Social Sciences (SPSS) version 20.0. Descriptive analysis was provided by absolute frequency (n) and relative (\%) for categorical data and the average and standard deviation for quantitative variables. The normality of the data was tested using Kolmogorov-Smirnov (KS). To compare averagebetween groups of metabolic expenditure was used Student's $t$ test for parametric distribution pattern variables and Mann-Whitney nonparametric distribution of variables. It was considered for analysis purposes $\mathrm{p}<0.05$.

\section{Results}

After data collection, a sample was constructed containing 50 pregnant women between the second and third trimester.

The average age of the participants was of 27.40 years $( \pm 5.93)$ body weight of $66.55 \mathrm{~kg}( \pm 9.40)$, mean height of $160.77 \mathrm{~cm}( \pm 0.05)$, number of pregnancies $2.24( \pm 0.95)$ and mean time 25.48 weeks of gestation $( \pm 6.82)$. Prevailed in pregnant study with work activity outside the home $(42.0 \%)$, with high school education $(60.0 \%)$, uniformed marital status (72.0\%), higher family income than two minimum wages $(34.0 \%)$ and in the third trimester of pregnancy $(58.0 \%)$. The sample is characterized in Table 1.

Table I Sample characterization

\begin{tabular}{|c|c|c|c|c|c|}
\hline \multirow[t]{2}{*}{ Age years } & \multicolumn{4}{|c|}{ Work activity } & \multirow[b]{2}{*}{$\%$} \\
\hline & $\mathrm{n}$ & $\%$ & & $\mathrm{n}$ & \\
\hline 18-23 years & 16 & 32 & home & 19 & 38 \\
\hline $24-29$ years & 17 & 34 & Work out & 21 & 42 \\
\hline $30-35$ years & 13 & 26 & Student & 6 & 12 \\
\hline $36-40$ years & 3 & 6 & Uninformed & 4 & 8 \\
\hline$>40$ years & 1 & 2 & & & \\
\hline Total & 50 & 100 & & 50 & 100 \\
\hline \multirow[t]{2}{*}{ Education } & & & Marital status & & \\
\hline & $\mathrm{n}$ & $\%$ & & $\mathrm{n}$ & $\%$ \\
\hline Fundamental. & 5 & 10 & Single & 12 & 24 \\
\hline Medium & 30 & 60 & Unity & 36 & 72 \\
\hline Sup. Incomplete & 3 & 6 & Uninformed & 2 & 4 \\
\hline Higher & 12 & 24 & & & \\
\hline Total & 50 & 100 & & 50 & 100 \\
\hline \multicolumn{3}{|c|}{ Gestational quarter } & \multicolumn{3}{|c|}{ Household income (SM *) } \\
\hline & $\mathrm{n}$ & $\%$ & & $\mathrm{n}$ & $\%$ \\
\hline 2nd quarter & 21 & 42 & Up to I salary & 14 & 28 \\
\hline \multirow[t]{2}{*}{$3 r d$ quarter } & 29 & 58 & I-2 wages & 14 & 28 \\
\hline & & & $\begin{array}{l}\text { > Than } 2 \text { wages Not } \\
\text { Telling }\end{array}$ & 17 & 34 \\
\hline Total & 50 & 100 & & 50 & 100 \\
\hline
\end{tabular}

*SM=Minimum wage of R\$954.00-Decree No. 9255, DE 29, 2017 DECEMBER, Official Gazette (Brazil Goverment)- Section I-Extra Edition -D-29/I2/20I7, Page 2. 
Prior to the $56.0 \%$ of the sample pregnancy practiced some kind of physical activity and during pregnancy was reduced to $32.0 \%$. The physical activity profile in pregnant women before and during pregnancy is described in Table 2 .

The data showed the prevalence of active pregnant women in household activities (56.0\%) and transport (74.0\%), and insufficiently active pregnant women in caring for people $(64.0 \%)$, occupation $(66.0 \%)$, sports $(94.0 \%)$ and leisure $(66.0 \%)$. Table 3 shows the following describes the percentage of pregnant women in the level of physical activity per trimester at different times.
Table 2 Profile of physical activity

\begin{tabular}{lll}
\hline Physical activity & Before pregnancy & During pregnancy current \\
\hline & $\mathrm{n}(\%)$ & $\mathrm{n}(\%)$ \\
Yes & $28(56.0)$ & $16(32.0)$ \\
Not & $20(40.0)$ & $34(68.0)$ \\
Did not inform & $2(4.0)$ & $0(0.0)$ \\
Total & $50(100.0)$ & $50(100.0)$ \\
\hline
\end{tabular}

Table 3 Description of the percentage of pregnant women in the level of physical activity per quarter

\begin{tabular}{|c|c|c|c|c|c|c|c|c|}
\hline \multirow[b]{2}{*}{ Domestic activities } & & & \multicolumn{2}{|c|}{$\begin{array}{l}\text { Second trimester } \\
(\mathrm{N}=2 \mathrm{I})\end{array}$} & \multicolumn{2}{|c|}{$\begin{array}{l}\text { Third trimester } \\
(\mathrm{N}=29)\end{array}$} & \multicolumn{2}{|c|}{$\begin{array}{l}\text { Total } \\
(\mathrm{N}=50)\end{array}$} \\
\hline & & & $\mathrm{n}$ & $\%$ & $\mathrm{n}$ & $\%$ & $\mathrm{~N}$ & $\%$ \\
\hline \multirow[t]{4}{*}{ Domestic activities } & insufficiently active & sedentary & 0 & 33.3 & 0 & 51.7 & 0 & 44 \\
\hline & & Light & 7 & & 15 & & 22 & \\
\hline & active & moderate & 8 & 66.7 & 8 & 48.3 & 16 & 56 \\
\hline & & vigorous & 6 & & 6 & & 12 & \\
\hline \multirow[t]{4}{*}{ Take care of people } & insufficiently active & sedentary & 2 & 42.9 & 3 & 79.3 & 5 & 64 \\
\hline & & Light & 7 & & 20 & & 27 & \\
\hline & active & moderate & 8 & 57.1 & 6 & 20.7 & 12 & 36 \\
\hline & & vigorous & 4 & & 0 & & 6 & \\
\hline \multirow[t]{4}{*}{ Occupation } & insufficiently active & sedentary & 13 & 71.4 & 14 & 62.1 & 27 & 66 \\
\hline & & Light & 2 & & 4 & & 6 & \\
\hline & active & moderate & 0 & 28.6 & 5 & 37.9 & 5 & 34 \\
\hline & & vigorous & 6 & & 6 & & 12 & \\
\hline \multirow[t]{4}{*}{ sports } & insufficiently active & sedentary & 4 & 90.5 & 8 & 96.6 & 12 & 94 \\
\hline & & Light & 15 & & 20 & & 35 & \\
\hline & active & moderate & I & 9.5 & I & 3.5 & 2 & 6 \\
\hline & & vigorous & 1 & & 0 & & I & \\
\hline \multirow[t]{4}{*}{ Locomotion } & insufficiently active & sedentary & 0 & 19.1 & 0 & 37.9 & 0 & 26 \\
\hline & & Light & 4 & & $\mathrm{II}$ & & 13 & \\
\hline & active & moderate & 7 & 81 & II & 62.1 & 18 & 74 \\
\hline & & vigorous & 10 & & 7 & & 19 & \\
\hline \multirow[t]{4}{*}{ Recreation } & insufficiently active & sedentary & 0 & 61.9 & 1 & 69 & I & 66 \\
\hline & & Light & 13 & & 19 & & 32 & \\
\hline & active & moderate & 6 & 38.1 & 9 & 31 & 15 & 34 \\
\hline & & vigorous & 2 & & 0 & & 2 & \\
\hline
\end{tabular}

The average energy expenditure (in METs) physical activity of the volunteers was: with household chores in the second trimester was $22.75( \pm 11.24)$ and the third quarter of $20.17( \pm 12.27)$ in caring for people during the second quarter showed $24.83( \pm 22.92)$ and in the third quarter $13.21( \pm 11.24)$, the occupational tasks during the second quarter was $25( \pm 44.57)$ and third in $18.04( \pm 22.61)$, in sports activities and exercises in the second quarter was $1.45( \pm 2.62)$ and third quarter of $0.83( \pm 0.84)$, compared to the second quarter of locomotion $5.25( \pm 4.66)$ and the third quarter of $5.06( \pm 4.54)$. In total, there was no statistical difference between the quarters as the METs weekly spending.The energy expenditure in the sample by comparing MET between trimesters of pregnancy are shown in Table 4 . 
Table 4 Description of energy expenditure spent on METs (intensity average energy expenditure weekly)

\begin{tabular}{|c|c|c|c|c|c|}
\hline & \multicolumn{2}{|c|}{ 2nd quarter $(\mathrm{N}=\mathbf{2} \mathrm{I})$} & \multicolumn{2}{|c|}{ third quarter $(\mathbf{N}=29)$} & \multirow{2}{*}{$\mathbf{P}$} \\
\hline & $\mathbf{M}$ & DP & $\mathbf{M}$ & DP & \\
\hline Housework & 22,75 & 11.24 & 20.15 & 12.27 & $0.640 *$ \\
\hline Take care of people & 24.83 & 22.92 & $|3.2|$ & 11.24 & $0.790 *$ \\
\hline Occupation & 25 & 44.57 & 18.04 & 22.61 & $0.653 \dagger$ \\
\hline Sports/Exercises & 1.45 & 2.62 & 0.83 & 0.84 & $0.131 *$ \\
\hline Locomotion & 5.25 & 4.66 & 5.06 & 4.54 & $0.88 \dagger$ \\
\hline Leisure activities & 35.66 & 17.72 & 29.14 & 16.48 & $0.207 \dagger$ \\
\hline Total week & 114,95 & 69.1 & 86.46 & 39.53 & $0.166 *$ \\
\hline
\end{tabular}

\section{Discussion}

It is known that physical activity cooperates to improve the quality of life and reduce pain in the general population6 and when talking, there was a paradigm shift in relation to the recommendations of rest and interruption of work activities, passing to the stimulus 13 It is known that physical activity works for improving the quality of life and reduce pain in general population ${ }^{6}$ and about pregnant women there is no difference. There is a paradigm shift in relation to the rest of recommendations and interruption of work activities, through the encouragement to the practice of exercises in that period..$^{13}$ In the present study we observed an increase in the prevalence of sedentary women during pregnancy, when observing the reference to physical activity before pregnancy. This information concerned because there has been a predisposition to the decrease in activity level given advent of pregnancy.

In a study of perception of sedentary behavior in pregnant teenagers $86 \%$ of the volunteers said that had stopped exercising in the first trimester of pregnancy for reasons ranging from dislike of exercise, indisposition, illness, fear of falls and abortion. ${ }^{2}$

It has also been recognized in studies on the subject that there is a tendency for the decline of physical activity levels with the onset of gestation, ${ }^{3,8}$ the main reasons for this finding being the difficulty to join the practice exercises for pregnant women, and beyond also present between each other, doctors and caregivers some uncertainty and doubts about the safety of the practice. ${ }^{5}$

In the case of pregnant women the benefits of an active lifestyle are numerous, in addition to the protective effect produced against prematurity, disturbances with the amniotic fluid, the appearance of edema and gestational diabetes ${ }^{6}$. For this reason, when it comes to health promotion, the need for constant information and incentives for activity during pregnancy is emphasized. ${ }^{5}$ One fact is that, faced with the recommendations of health professionals for leisure physical activities, pregnant women are three times more likely to exercise when compared to pregnant women who did not receive such incentives. ${ }^{11}$

In our sample, there was a tendency to decrease in the average METs expended for all tasks evaluated by QAFG when advanced from the second to the third trimester, it is important to note the decrease by almost $50 \%$ for the activities to take care of people and sport, but a tiny reduction in scores for the domestic activities and mobility.

Still, most of the interviewed women were classified as active for domestic activities in the second trimester. In the third quarter, the prevalence was insufficiently active, but no sedentary, or at least the light pattern of activity was maintained.

It is possible to infer to this result the fact that despite decrease in domestic practice in the course of pregnancy, the population is still performing their duties in the home, even those women who have work activity outside the home. And this slight reduction in the number of active women in the third trimester group may be related to increased physical discomfort, pain and fatigue resulting from the pregnancy progress. In our sample, all volunteers reported some level of physical discomfort to the initial interview.

It is in the third trimester that the woman tends to decrease the intensity of the exercise due to the weight gain and other discomforts that can cause limitations. ${ }^{5}$ In a study conducted by Assis et al. ${ }^{6}$ several pregnant women reported uncomfortable pain that could be limiting in their domestic activities, but since there were no other people to perform the task, they resisted the pain during their performance.

To the tasks of caring for people observed a large number of insufficiently active pregnant women in the third quarter. An important observation is that prevailed in this study multiparous women, that is, who performed more intense activities with their children and dependents, and accepted that with advancing pregnancy had a tendency to be more prone to physical fatigue, making it difficult to carry out certain activities of care and may be justifiable factor for the pattern found.

In early pregnancy, mothers tend to decrease the intensity with their dependents, for example, play, run and bear children and also pregnant women who feel pain tend to be more sedentary in caring for others compared to pregnant women who do not feel pain. ${ }^{6}$

Less than half the present sample exercised paid occupation within that group prevailed insufficiently active pregnant women in both the second and in the third trimester on occupation duty. As the pregnancy period is known for constant changes, women tend to perform mild activities, in order to not cause extra pain resulting from exacerbated efforts, which may explain this result.

Lent et al. ${ }^{14}$ emphasize that the greater the pain and fatigue, the lower the performance and ability to perform the task, and there is a tendency to dislike the task, making them less relevant. Lima, Bishop and Cordeiro ${ }^{3}$ found a significant reduction in household and occupation activities during gestation and point out that most women change their pattern of activities in order to adjust physiologically and psychologically. Regarding exercise and sports during the gestational period, the sample was classified as sedentary or not active in both 
quarters. Corroborating with the present study, a study carried out in Fortaleza/CE (Brazil) with 305 pregnant women was observed that $80 \%$ of the sample had a mild or sedentary pattern. ${ }^{5}$

It is possible to deduce that what characterizes this finding in the present study are physical inactivity habits before pregnancy presented by this population coupled with the lack of information of the benefits of physical activity during this period, pointing this way the need for emphasize practical advice for health professionals working in prenatal program regarding the exercises and their benefits for both the mother and the fetus.

Many are the focus of study in this area, but the doubts and questions that lead to the reduction of predominate 15 , and it is necessary to emphasize the importance of clarification by health professionals regarding the uncertainties, fears and insecurity in the execution of exercises during pregnancy, Many are the study focus in this area, but dominated by doubts and questions that lead to reduction of activity ${ }^{15}$ being necessary to emphasize the importance of the clarification by health professionals as the uncertainties, fears and insecurity on exercising during pregnancy, stimulating the mother in the performance of such practice. ${ }^{3}$

Another factor found is that women who already performed physical activity before pregnancy were seven times more likely to maintain the activity compared to women who did not exercise before the pregnancy period ${ }^{11}$.

Participants were shown to be active in mobility activities, both in the second as the third quarter. This can be justified due to the municipality's characteristics where the study took place, being a small town and there is no public transport, requiring that women make their locomotion walk to the supermarket, market and health services, for example, and using private transport only to carry out emergency activities and go to more distant places in a reduced form.

Regions of low socioeconomic levels may be the influence of walking influence on locomotion16, leading to discussion at international levels, in which Brazilian pregnant women have spent six times as much energy in displacement activities as American pregnant women. ${ }^{8}$ Regions of low socioeconomic status may be the major influence factor to walk in regards to locomotion ${ }^{16}$ leading the discussion to international levels, in which Brazilian pregnant women have spent energy spent six times larger displacement activities compared to American pregnant women. ${ }^{8}$

The leisure-oriented practices are limited in this study. Leisure tasks in this study were defined by insufficiently active women in the second and third trimester of pregnancy. This result may be related to the cultural reality of the city and no relaxation sites, also emphasizing the insecurity and crime afflicting the general population. Most of the volunteers of the research has not habits to practice leisure activities and fun, making it stay in your home environment. Carvalhaes et al. ${ }^{8}$ show that Brazilian pregnant women have spent average energy in leisure activities four times less related to American pregnant women.

Moreover, these same women perform other activities over a longer period of time leaving no space left for fun and relaxation, that is, during pregnancy women tend to get bored easily and consequently confines themselves to walking. ${ }^{1}$

Cherry et al. ${ }^{17}$ also point to the occurrence of an urban expansion and reduction of open spaces for physical activity and leisure, associated with this, problems such as violence, work and technology hinder the adoption of healthy habits.
Although there has been decrease in the average intensity of the weekly metabolic expenditure (METs) to all the activities, the results show no statistical difference when compared groups (second and third trimester). Note that the sample size may have been a limiting factor for statistical significance with. physiological criteria and the pregnant woman's health have not been considered, which opens up opportunities for further research aimed at this problem.

There is a need for interventions aimed at health and public policies focused on promoting enabling environments for physical activities, as well as need to train health professionals, particularly Primary Care, aware of their supportive role. Expected to instigate promoting research about the intention and behavior of the mother and of the factors that would allow other interventions to make it a regular practice in pregnant women a daily habit as a strategy designed to promote health and quality of life for the mother-fetus. This study showed a prevalence of active pregnant women with housework and commuting, sedentary or slightly active in the tasks related to sports/ exercise, leisure, care for people and occupation.

The data showed that, in the course of pregnancy, most pregnant women reduced their activities, prevailing in inactive women research, being considered a worrisome condition as it relates to women's health. Thus, it emphasizes the need for advice and recommendations for physical activity by managers and health professionals in primary care and prenatal program to promote the health of mother and fetus and adherence to a healthy lifestyle in view of the benefits that physical activity has both pre, as postpartum.

\section{Contributions of authors}

Matos MLM, participated in the project design, data collection, analysis and interpretation of data, drafting of the manuscript. Nunes $\mathrm{CM}$, participated in the data collection, analysis and interpretation of data, drafting of the manuscript. Andrade ES participated in the design and research project, relevant critical review of the intellectual content. Matos GSR, participated in the design and research design, analysis and interpretation of data, critical review of the relevant intellectual content, final approval of the version to be published.

\section{Funding}

My research project was partially or fully sponsored by Fundação de Amparo a Pesquisa do Estado do Amazonas FAPEAM with grant number PIB-S-0063/2017.

\section{Acknowledgement}

The study participants because without them this project would not have been executed. In the Foundation support the Amazonas State Research - FAPEAM through Program to support scientific research - PAIC.

\section{Conflict of interests}

The authors declare no conflict of interest.

\section{References}

1. Coutinho CE, Smith CB, CMB Chaves, et al. Pregnancy and childbirth: What changes in the lifestyle of women who become mothers ?. Rev ESC Enferm USP. 2014;48(2):17-24.

2. ES Andrade, Olive G, Medeiros DL, et al. sedentary perception and associated factors in pregnant adolescents in the city of Coari, Amazonas State, Brazil. Rev Pan-Amaz Saude. 2010;1(4):35-41. 
3. Lima JM, Bishop W Lamb AL. Influence of physical activity on quality of life of pregnant women: a cross sectional study. RevResearch in Physical Therapy. 2016;6(4):395-401.

4. Giacopini SM, Oliveira DV, Araújo APS. Benefits and recommendations of physical exercise during pregnancy. Rev BioSalus. 2016;1:1-9.

5. Birth SL, Godoy AC, Surita FG, et al. Recommendations for physical exercise in pregnancy: a critical review of the literature. Obstet Gynecol. 2014;36(9):423-431.

6. Assisi TR, JG Mendes, Rezende FR, et al. Impact of musculoskeletal pain at the level of physical activity in low-risk pregnant women. Rev Move. 2016;9(3):430-440.

7. Jjo Toscano, EP Egypt. The influence of physical inactivity on the prevalence of low back pain. Rev Bras Med Esporte. 2001;7 (4):132-137.

8. Carvalhaes MABL, Martiniano ACA, Malta MB, et al. physical activity in pregnant women attended in primary health care. Rev Public Health. 2013;47(5):958-967.

9. Ferreira AFNF, NTA Neto, Morales AP, et al. Physical activity and pregnancy: risks and benefits. Persp online: Cell Biology \& Health. 2014;14(4):1-8.

10. Baracho E. Physiotherapy applied to women's health. 5th ed, Rio de Janeiro: Guanabara koogan; 2013.
11. Romero SCS, CH Kurashima, Romero, et al. The influence of health professionals about the practice of leisure physical activity in pregnant women. Thinking Practice. 2015;18(3):584-599.

12. FT Silva, Costa FS. Physical activity level assessment during pregnancy. Obstet Gynecol. 2007;29(9):490.

13. Surita FG, SL Nascimento Silva JLP. Physical exercise and pregnancy. Obstet Gynecol. 2014;36(12):531-534.

14. Lent C, Smith C, MF Secca, et al. Marques translation, adaptation and evaluation questionnaire psicométricado activity record (ACTRE). Acta Rheumatol Port. 2017;42:168-175.

15. Rebesco DB, WC Souza Lima VA, Grzelczak MT, et al. Action of exercise during pregnancy: a review study. Arch Health Invest. 2016;5(6):311-317.

16. Teixeira IP, Nakamura PM, Kokubun E. walk Practice leisure and travel and association with socioeconomic factors and perceived environment in adults. Rev Bras Cineantropom Performance Hum. 2014;16 (3.):345358 .

17. Cherry FG, CC Beck, cherry CPS, et al. Prevalence and sociodemographic and environmental factors associated with physical activity in leisure time and displacement in adults. Motricity. 2014;10(1):3-13. 